\title{
A CONTENT OF HEAVY METALS IN E-WASTE: A COMPARATIVE STUDY OF VARIOUS LIGHTG SOURCES
}

\author{
Barbora RANTOVÁ1; Martin ŠOTNAR ${ }^{1}$; Milan GERŠL ${ }^{1}$; Jan MAREČEK ${ }^{1}$ \\ ${ }^{1}$ Mendel University in Brno, Faculty of AgriSciences, Department of Agricultural, Food and \\ Environmental Technology, Zemědelská 1, 61300 Brno, Czech Republic
}

\begin{abstract}
Demand for light sources increases with the increasing energetic, technologic and economic requirements of society. The lifetime hours of lamps are longer; however, such a waste still makes up a portion of waste production. The content of toxic metals is one of the factors that influences the environmental impact during their life cycle. Discharged light sources are separated, recycled or disposed. The sorted material can be reused as a secondary raw material, or the waste can be energetically recovered in an incinerator. One of the most disadvantageous options is landfill deposition. The separated fractions of such waste can be reused in terms of lowering the amount of waste and enhancing the circularity. Although compact fluorescent lamps and LEDs are energetically more convenient, their material requirements are more demanding.
\end{abstract}

Purpose: The aim of the study, was to evaluate the heavy metal composition regarding environmental factors, considering the lifetime hours and luminescence.

Design/methodology/approach: The content of heavy metals of fluorescent lamp, LED lamp and incandescent light bulb was studied using the XRF analyser. The illuminance of the light sources was measured by a lux meter.

Findings: Based on the results, the LED light sources seem to be the most convenient. From the analysis, these light sources contain the lowest amount of copper and lead, also from the perspective of the lifetime hours and already existed collecting system.

Keywords: light sources, heavy metals, X-ray fluorescence, LED, CFL, the incandescent lightbulb

\section{Introduction}

Light sources, as energy-related products, figure with a significant potential regarding lowering environmental impact and have a positive achievement in energy. According to the EC directive 2009/125/EC, there are certain parameters to be followed to improve their life cycle impacts on the environment (Directive EU). Due to the directive requirements, gradually manufacturers and consumers have been converting from incandescent light bulbs to compact fluorescent lamps (CFL) or light-emitting diodes (LED). These can use $70 \%$ to $85 \%$ less energy compared to incandescent light bulbs. Their lifetime represents 10 to 50 times longer period (Lim et al., 2012). Annexe 1 of the European directive sets, among others, expected parameters in terms of waste generation, material recovery and pollution in each environmental element, such as soil, water or atmosphere.

In the Czech Republic, light sources undergo regulation 542/2020 Sb. dealing with a takeback waste collection. In 2019 the number of electronic products 
undergoing takeback system was 236297 tons, whereas the amount of those that were recollected was 101319 tons. These numbers represent all types of electronic devices, where light sources take their part too (Cenia, 2019). According to one of the biggest recycling companies in the Czech Republic, Ekolamp, in 2020 there were 587 tons of light sources handed over for recyclation. From these $93 \%$ was materially recovered. The total amount of municipal waste produced in 2019 was around 5,76 million tons. This waste includes the waste from a separate waste collection system (Cenia, 2019). Recycling is based on a volunteer action, although every consumer pays for recyclation via purchase price. Several legislation documents and policies have been applied in terms of lowering the energy consumption regarding the environmental impact and climate change, such as the Directive 2009/125/EC of requirements for eco-design or the European Regulation 2017/1369 of eco-labelling or the Directive 2012/19/EC on waste electrical and electronic equipment.

In Europe, light consumption in households represents around $20 \%$ to $30 \%$ of the overall domestic consumption. Compact fluorescent lamps (CFL) represent a light source that has a longer lifetime cycle and consumes less energy than the equivalent of the incandescent bulb. These light sources have been replacing the incandescent and halogen light sources because of their higher capacity to fulfil the EU targets set up for energy consumption (2005/32/EC). However, the number of hazardous components, such as toxic metals mean a possible threat, when being disposed improperly, mainly as a part of municipal waste being disposed at the landfill. Moreover, the recyclation and copper recovery not only from incandescent light bulbs, can contribute to the primary ore conservation and save up to $85 \%$ of production energy, therefore decrease the negative environmental impact of production processes (Isildar et al., 2018). In the case of a function, $100 \mathrm{~W}$ incandescent lamp can be represented by $23 \mathrm{~W}$ CFL, which lasts 8 to 10 times longer period and consumes from 2 to 5 less energy power (Khan et al.,2011).

In developed countries, $40 \%$ of electronic waste that includes light sources, ends up in landfills. In some countries, e.g. Iran, certain light sources become a part of a municipal waste stream (Taghiopur et al., 2014). According to Ghosh et al. (2015) illegal sites can contain 100 times more heavy metal or polycyclic aromatic hydrocarbon pollutants (Cucchiella et al., 2015; Gosh et al., 2015).

In general, recycling electronic waste represents a strategy to support environmental protection by proper disposal and thus avoiding contamination. Waste from LEDs and CFLs has a higher potential risk in human health effects and impact on the environment while being disposed. Therefore, this study aims to compare different types of light sources from the perspective of the content of heavy metals and illuminance.

\section{Methodology}

For the purpose of this study, three types of light sources were used: incandescent light bulbs, compact fluorescent lamps (CFL) and light-emitting diodes (LED). LEDs and CFL were claimed to be equivalent to $100 \mathrm{~W}$ incandescent light bulb by 
the producer. Three samples of each type of light sources were homogenized and prepared for X-ray fluorescence (XRF) analysis. Parameters such as luminescence and heavy metal content were measured, using lux meter Tesla PU150 and XRF analyser Niton XL3t Goldd+, respectively. Also, lifetime hours and economic aspects were considered. The lifetime hours of CFLs and LEDs presented by the producer were 8000 and 25000 hours. For this study, household conditions were taken into account and the used XRF analyser was calibrated by a producer. The samples of each light sources were measured three times. Fig. 1 describes the measurement of illuminance. A lightbulb was placed in a table lamp at a height of $1 \mathrm{~m}$, with incident rays pointing down to the lux meter.

(2)

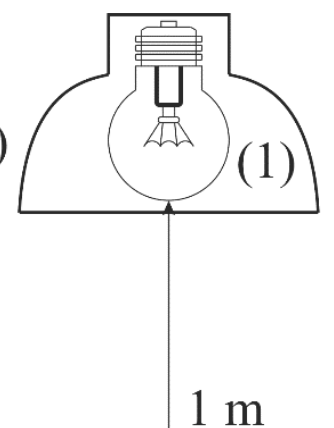

\section{(3)}

Figure 1. The principle of illumination measurement, where the table lamp was used to imitate the office environment.

(1) studied light source, (2) lamp-shade and (3) lux meter.

\section{Results and discussion}

The content of heavy metals determined from the XRF measurements (see Fig. 2 ) is presented in Table 1. These results show, that even though the incandescent lightbulbs contain the lowest amount of copper, considering the lifetime hours of one LED vs. lifetime hours of one incandescent bulb, disposing one incandescent lightbulb would produce $0,129 \mathrm{~g}$ of $\mathrm{Cu}$, whereas one LED, lasting the same time would produce only $0,012 \mathrm{~g}$ of copper waste. From this point of view, LED light sources seem to be more convenient. Another advantage is the price when equivalently one LED is cheaper than equally time lasting classic incandescent bulbs. The same occurs in the case of CFL light sources when the amount of $\mathrm{Cu}$ rises to 2,62 $\mathrm{g}$ comparing with one LED. Similar contents of copper were compared in the study by Zamprogno Rebello et al., (2019), where the authors claimed $\mathrm{Cu}$ to be the second most abundant metal analysed in LEDs and CFLs, after aluminium. Copper is represented from $0,021 \%$ to $0,031 \%$ in LEDs, which is the amount, comparable 
only with the incandescent light bulbs from the analysis. CFLs were claimed to contain from $0,0005 \%$ to $0,111 \%$. The differences may be caused by a different way of leaching $\mathrm{Cu}$ from a sample, a method of analysis, but also the research does not provide information about power consumption (Zamprogno-Rebello et al., 2019).

The highest amount of $\mathrm{Pb}$ was analysed in the incandescent light bulb. Since $\mathrm{Pb}$ is an element that occurs in the environment naturally, the higher levels can be caused by e.g. old plumb systems, mining or industrial activities. Leaded fuels are decreasing in their use, but their remains are still detectable in certain sites. Its occurrence is detected up to 8 inches in soil and since it is naturally immobile and accumulates in biological systems, elimination of $\mathrm{Pb}$ without direct remediation means a long-term environmental exposure (Tangahu et al., 2011).

In the case of $\mathrm{Pb}$, the other factors might determine the choice of light source one can use. One of the factors may be energy, which can be lowered by the uptake but also other material demand such as aluminium or gallium. Comparing LED and CFL light sources, LEDs are $40 \%$ more energy-efficient and mercury-free. From this point of view, it is more convenient to consider LED usage (Liu et al., 2020)

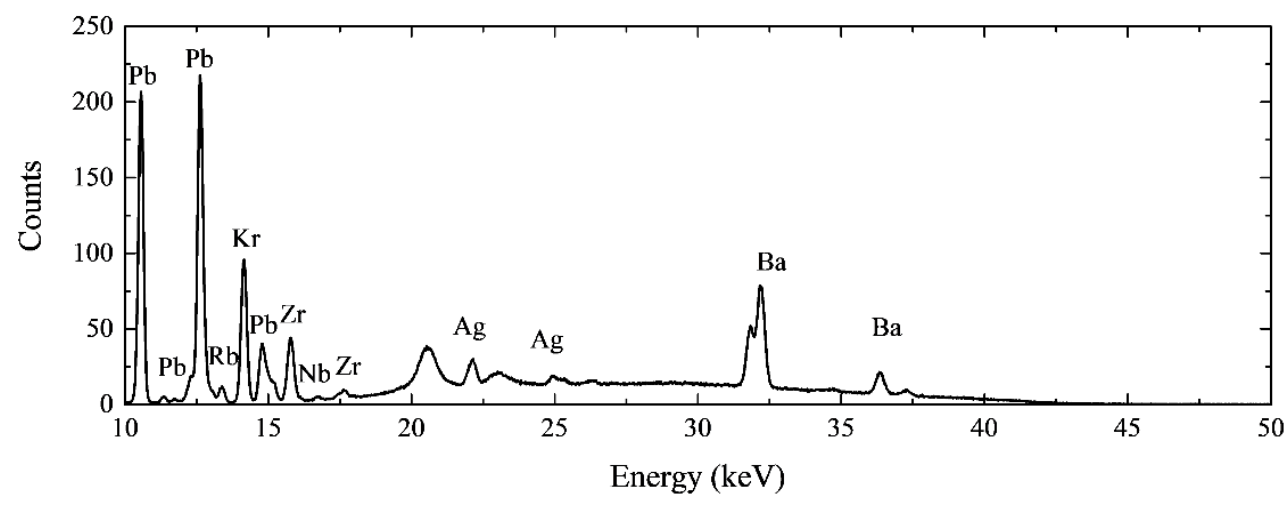

Figure 2. An example of the XRF spectrum of the incandescent light bulb

The measurement of illumination shows that the results for CFL and LED are consistent with each other, within the errors. However, the results in the case of incandescent lightbulb show, that the illumination is significantly higher than in the case of the other light sources using in this study. These discrepancies could be caused by the bulb shape, and also due to the values did not match the information on the package. The second reason could be explained by the different techniques of photometric quantities. 
Table 1. Results of measuring the lighting sources

\begin{tabular}{|c|c|c|c|c|c|c|c|}
\hline $\begin{array}{c}\text { Power } \\
\text { consumptio } \\
\mathrm{n}\end{array}$ & $\begin{array}{c}\text { Lifetime } \\
\text { hours }\end{array}$ & $\begin{array}{c}\text { Illumination } \\
{[\mathrm{lux}]}\end{array}$ & $\begin{array}{c}\text { Weight } \\
\text { of the } \\
\text { light } \\
\text { source } \\
{[\mathrm{g}]}\end{array}$ & $\begin{array}{c}\text { Content } \\
\text { of } \mathrm{Cu} \\
{\left[10^{-1} \%\right]}\end{array}$ & $\begin{array}{c}\text { Content } \\
\text { of } \mathrm{Cu}^{1} \\
{[\mathrm{~g}]}\end{array}$ & $\begin{array}{c}\text { Content } \\
\text { of } \mathrm{Pb} \\
{\left[10^{-2} \%\right]}\end{array}$ & $\begin{array}{c}\text { Content } \\
\text { of } \mathrm{Pb}^{1} \\
{[\mathrm{~g}]}\end{array}$ \\
\hline $\begin{array}{c}\text { Incandescen } \\
\text { t lightbulb } \\
100 \mathrm{~W}\end{array}$ & 1000 & $320 \pm 32$ & $\begin{array}{c}28.61 \pm 1 \\
.42\end{array}$ & $\begin{array}{c}0.18 \pm 0 . \\
024\end{array}$ & 0.129 & $\begin{array}{c}76.4 \pm 4 . \\
7\end{array}$ & 5.463 \\
\hline $\begin{array}{c}\text { CFL } \\
21 \mathrm{~W}\end{array}$ & 8000 & $200 \pm 20$ & $\begin{array}{c}77.29 \pm 1 \\
.33\end{array}$ & $\begin{array}{c}11.30 \pm 1 \\
.37\end{array}$ & 2.620 & $\begin{array}{c}3.5 \pm 0.0 \\
53\end{array}$ & 0.081 \\
\hline LED & 25000 & $165 \pm 17$ & $\begin{array}{c}35.18 \pm 0 \\
.15\end{array}$ & $\begin{array}{c}2.78 \pm 0 . \\
365\end{array}$ & 0.098 & $3.3 \pm 0.1$ & 0.012 \\
\hline
\end{tabular}

${ }^{1}$ This value is equivalent to 25000 lighting hours

\section{Conclusion}

The study was focused on the comparison of different types of light sources from the perspective of the content of heavy metals. The main results could be summarised as follows:

- The results show, that in the case of $\mathrm{Cu}$, the compact fluorescent lamps contain the largest amount of this metal, with respect to lifetime hours. In the case of $\mathrm{Pb}$, the highest content was analysed in incandescent lightbulb waste, also considering the lifetime hours.

- The measurement of illumination shows that the results for CFL and LED are consistent with each other, within the errors. On the other hand, the results in the case of incandescent lightbulb show, that the illumination is significantly higher than in the case of the other light sources used for this study.

- From the point of view of the consumer, the CFL are in retreat, mainly due to its recycling is laborious and costly.

Based on the presented results, it can be concluded, that the LED light sources seem to be the most convenient. From our measurement, these light sources contain the lowest amount of copper and lead. Considering their lifetime hours, the amount of waste should be the lowest, also incandescent lightbulbs happen to be a part of municipal waste, whereas the separate collection system for CFL and LEDs has been already set up. LED sources can be also collected separately from other light sources, with electronic waste. 


\section{References}

1. Cucchiella, F., D’Adamo, I., Lenny Koh, S.C., Rosa, P. (2015), Recycling of WEEEs: an economic assessment of present and future e-waste streams. "Renewable Sustainable Energy", 51, pp. 263-272, http://dx.doi.org/10.1016/j.rser.2015.06.010

2. Directive 2005/32/EC of the European Parliament and of the Council: establishing a framework for the setting of ecodesign requirements for energy-using products and amending European law (Strasburg, 2005, 6 July 2005, 2005/32/EC)

3. Directive 2009/125/EC of the European parliament and of the council: establishing a framework for the setting of ecodesign requirements for energy-related products. European Law (Strasbourg, 2009, 21 October 2009, 2009/125/EC)

4. Ghosh, B., Ghosh, M.K., Parhi, P. (2015). Waste printed circuit boards recycling: an extensive assessment of current status. "Journal of Clean Production", 94, pp. 5-19., http://doi.org/10. 1016/j.jclepro.2015.02.024

5. https://www.cenia.cz/wp-content/uploads/2021/02/Statisticka_Rocenka_ZP_CR-2019.pdf (access date: 29-4-2021)

6. https://www.ekolamp.cz/data/web/download/ekolamp-2020-final.pdf (access date: 25-22021)

7. https://www.europarl.europa.eu/sides/getAllAnswers.do?reference=P-20090146\&language $=\mathrm{EN}$ (access date:12-2-2021)

8. Iş1ldar A., Rene E.R., Hullebusch E.D., Lens P.N.L. (2018), Electronic waste as a secondary source of critical metals: Management and recovery technologies, „Resources, Conservation and Recycling", 135, pp. 296-312, http:// doi:10.1016/j.resconrec.2017.07.031

9. Khan, N., \& Abas, N. (2011). Comparative study of energy saving light sources, "Renewable and Sustainable Energy Reviews", 15(1), pp. 296-309, http://doi:10.1016/j.rser.2010.07.072

10. Lim S.R., Kang D., Ogunseitan O.A., Schoenung J.M. (2012), Potential Environmental Impacts from the Metals in Incandescent, Compact Fluorescent Lamp (CFL), and LightEmitting Diode (LED) Bulbs, ,Environmental Science \& Technology”, 47, 2, pp. 1040-1047. http:// doi:10.1021/es302886m

11. Liu L., Keoleian, G.A. (2020), LCA of rare earth and critical metal recovery and replacement decisions for commercial lighting waste management, „Resources, Conservation and Recycling”, http:// doi:10.1016/j.resconrec.2020.104

12. Tangahu, B. V., Sheikh Abdullah, S. R., Basri, H., Idris, M., Anuar, N., \& Mukhlisin, M. (2011). A Review on Heavy Metals (As, Pb, and Hg) Uptake by Plants through Phytoremediation. "International Journal of Chemical Engineering", http:// doi:10.1155/2011/939161

13. Taghipour, H., Amjad, Z., Jafarabadi, M. A., Gholampour, A., \& Nowrouz, P. (2014). Determining heavy metals in spent compact fluorescent lamps (CFLs) and their waste management challenges: Some strategies for improving current conditions. "Waste Management", 34,7, pp. 1251-1256, http://doi:10.1016/j.wasman.2014.03.010

14. Zamprogno Rebello R., Weitzel Dias Carneiro Lima M.T., Yamane L.H., Ribeiro Siman R. (2020), Characterization of end-of-life LED lamps for the recovery of precious metals and rare earth elements, „Resources, Conservation and Recycling”, http:// doi:10.1016/j.resconrec.2019.104557 